\title{
Tourism improvement based on sustainable architecture and new functions of textures and historical buildings and their alterations
}

\author{
Ghazal TAHERI $^{1}$, Aghil EMAMghOLI ${ }^{2}$ \\ ${ }^{1}$ Master's student; internal architecture, Islamic Azad University of Abhar \\ Qazaltaheri@gmail.com \\ ${ }^{2}$ Assistant professor, architecture group, Islamic Azad University of Abhar \\ Aghil.emamgholi@gmail.com
}

\begin{abstract}
Doubtless, architecture is one of the invaluable and profitable resources of countries holding the necessary infrastructure of the industry or seeking to build them. Tourism is a complex of phenomena and relations coming from interactions among tourists, capitals, hosting governments and communities, scientific institutions, transformation firms, and hosting and control of the tourists. One of the lucrative tourist sources is artistic and architectural phenomena which stand for the civilization of each country as civilization is a combination of symbols and historical and cultural revelations that are evidences for fort and identity of a nation and their persistence among other nations and civilizations. One of these revelations and symbols is historical houses and textures that have mostly been museums or places of interest that are restored today. In these buildings, Iranian art and architecture reveals itself from the past and demonstrates its mutual effect. Taking care of cultural identity in building, least use of natural resources and life qualities, this architecture meets a lot of principles which are financially efficient. The aim of this paper is to introduce the patterns of sustainable architecture in old Iranian architecture; it also examines old houses particularly Jalil Arazi house in Ghazvin which is a bright example of sustainable architecture. Climate, ecology, atmosphere, building's body, appropriate form and beautiful design are some of the main factors in sustainable architecture. That's why Iranian architects have been welcome to anything looking good to the eye and have revealed it in traditional architecture; some of these visual scenes include patterns of decorative designs, stucco, glass works, sash windows, brickworks, etc. This paper has implemented on biblical and archival method by survey and is provided the results as a paper.
\end{abstract}

Keywords: Tourism, textures, historical buildings, sustainable architecture, modern applications.

\section{Introduction}

Historical protection or the protection of cultural heritage is a professional effort seeking for maintenance and keeping of important historical buildings, objects, and other findings. Development of the basics of protecting them in the second half of the twentieth century is 
considered as the main achievement of protecting activities in an international level. These principles or directions shown in charters, recommendations, statements, resolutions, and declarations are largely procured and passed by international institutions such as UNESCO and ICOMOS in order to preserve cultural heritages encompassing historical works, buildings, complexes, sites and cities around the world against different threats(Ahmad, Y. (2006), pp 292300.). All the times, historical sites have been a large issue in terms of preservation. There have been deep challenges and discussions on suitable means for behaving a historical texture when it needs developments and making a usable building for new applications or expansion of the building may be on the skedual. By introducing and examining these approaches and the case, the paper tries to take a right step toward preservation of cultural heritages and the promotion of architecture. Below, there provided a literature of the subject and some of the most important attitudes are analyzed and discussed.

Currently and in the field of architecture, the focus is on memorial buildings and houses but traditional urban places also need new management and interference for keeping cultural values and adapt the altering times. Answers to the question of development in historical sites are vastly various. There are people who build an internal architecture departed from the past that include Daniel Libskind and Frank Gary who believed that modern developments should simply represent the architecture of their time. Nevertheless, others such as Reymond Erit and Norm Tyler believed that preservation of the historical identity of the site is a must and should be prioritize in any circumstances, for any price. As time passed by, as a result of alterations in taste and ideas and also experience, sort of balance initiated between the two opposite extremes(CABE .(2001) : pp 622-644).

These two different attitudes resulted in two simple ideas toward the intervention in historical sites both having bad consequences in many cases. Altogether, when new changes happen to historical environments particularly for big and invaluable historical houses, they should be designed in a way that the new construction can be separable from historic texture for professional eye but the character of the historical site should be preserved. The differences between the two should not have an incongruent outcome or ugly contrast. In 1964, the Venice charter- the document of the founders of modern preservation movement-defined the goal of historical site's preservation and mending as such: "preserving of an art work is not less in value than preserving a historical document." But it also declared that any attachment to main elements should be distinguished from architectural composition and have a sign of contemporary architecture (ICOMOS (International council on monument and sites 1964 ).

For reviving and directing for rebuilding historical buildings, an authority was defined in 1977 as general dean for internal standards exactly based on the charter for the first time to revive and direct refinement of historical sites. The occupation was also designed to take care of the attachments that were simultaneously "different" in one specific building to be compatible and 
also for protecting the unity of building via taking care of materials, features, scale and proportions in historical sites (Penn, W. 2007).

In the chart and standards, it is assumed that any new structure would be built in modern way and for making sure of compatibility, it is necessary to be examined. Brolin explains: "There are different ways for designing a building in a way that it is concerned about its architectural texture; one can be a copy of architectural elements from the surrounding environment and the other one can use completely new forms for revival or even increasing the taste of current buildings. (Brolin, B. (1980) )."

Thus, there is a direct relationship among new designers, internal architecture and the way of meeting the needs of foreign or internal tourists as tourism is the combination of phenomena and relationships arising from mutual action among tourists, capital, governments and hosting communities, universities and transportation institutions, reception and control of tourists and other visitors.

As one of the main tourist destinations is historical textures and houses, considering sustainable development in architecture and old architecture has a great impact on this as new designs in the body of an old building doubles its attraction. On the nature of sustainable architecture one can say: the application of sustainable concepts and sustainable development on architecture has paved way for the formation of the phenomenon sustainable architecture! Main ideas of sustainable architecture include the use of the ability of application change, flexibility and latent energy (used for material production). Like other issues in architecture, the sustainable architecture encompasses its own principles and hold three phases: saving resources, design aiming at a return to the life cycle, design for those that have their own special strategies, and study and understanding this measure will extend the architect's view on the environment where he/she should design for.

\subsection{Discussion}

\section{Tourism development}

Tourism is a combination of phenomena and relations arising from the mutual interaction among tourists, capitals, government and hosting communities, universities and transportation institutions, and reception and control of tourists and other visitors.

Cultural heritage is one of the main pillars in tourism industry around the world that has gained more importance during last years. Historical art works, handy crafts, the form of residence, the style of life and all the values of a culture can be seen in cultural heritage of every nation.

Visiting ancient locations, memorials and museums is one of the different roles of tourism. This visit is considered as an efficient educational and social function that helps tourists with understanding the hosting society's culture. Furthermore, there visits and activities are very risky as the ancient and cultural heritage of a society can be vulnerable to harm and damage. Thus, overwhelming and unplanned utilizing of these sites for tourist attraction came across to 
criticisms as, in some cases, it results in the destruction of traditional and cultural signs of the hosting society and elimination of originality, identity and importance of the heritage. However, we should take in to account the fact that, due to the tourist visit, ancient sites, memorials and museums have increased in financial importance in recent years. To solve this contradiction, many countries have tried to introduce their cultural heritage come up to standards and preservation principles. Media are also back the efforts of introducing cultures to people. Nowadays, ancient heritage in societies is a very accessible good that is mesmerizing, pleasurable and relaxing (Payam UNESCO journal, tourism and culture, No. 350, pp.15).

Considering the fact that architecture plays a great role in tourism field, the issue of sustainable architecture would be of great importance in defining different concepts of sustainable development. The main ideas in sustainable development are the ability of change in application, flexibility, and latent energy. Like other elements in architecture, sustainable architecture has its own principles and rules and includes three phases: Saving resources, a design aiming for returning to life cycle, and design for those who have their own special strategies. Study and understanding this measure provides the architect with an extended view of the environment where the design should be done.

Tourism industry affects people's lives not only for its dimensional glory but for its undeniable role in improving their economy and culture. Although there is not a convention on economic effects of tourism among experts, they all agree on three subjects: The role of tourism in currency income, GDP, and employment.

\section{Sustainable architecture and the necessity of attention to old urban textures}

\subsection{Architectural principles in sustainable design}

Some of houses in Iranian traditional architecture enjoy features that put them among sustainable buildings. The principles that should be meet for a building to be considered as a sustainable architecture include:

The first principle; energy saving: The building should be built in a way that the need for fossil fuels comes down to the least amount.

The second principle; climate adaptation: buildings should be designed in a way that they can be harmonious with the climate and current energy resources in the site.

The third principle; least use of new materials: buildings should be designed in a way that they avoid new materials and after their shelf life, the material can be used for building new buildings.

The fourth principle; meeting the needs of the dwellers: In sustainable development, meeting the spiritual and physical needs are of great importance.

The fifth principle; harmony with the site: the building should gently be located in the ground of the site itself and should have congruity with the surrounding environment. 
The sixth principle; holism: In one specific project, all the principles of sustainable architecture should be visualized in order to make a healthy environment.

\subsubsection{The effect of climate on sustainable design}

Climate zoning formed based on different areas' climate and the effect that these features have on the formation of buildings and residual environments is very important in terms of increasing the shelf life, promoting qualitative comfort and internal spaces' hygiene and also in terms of the needed energy for controlling environmental circumstances of these spaces. Human needs in terms of dwelling include his/her need for forming a small shelter against uncomfortable environmental climate such as wind, rain, snow, keen sun light, and extreme hot and cold temperatures and environmental weather for meeting the need for warmth. Narrow alleys have provided houses and neighborhoods with shadow and natural airflow along with security. Adhering to wind, natural airflow were traveling from ally to the houses (internal yards) and passing through halls and Hashti was entering inside houses providing that with natural air conditioning. Some other effective climate factors in home designs include solar energy through windows, internal and external temperature difference, airflow speed in open and closed spaces, and internal air's steam pressure.

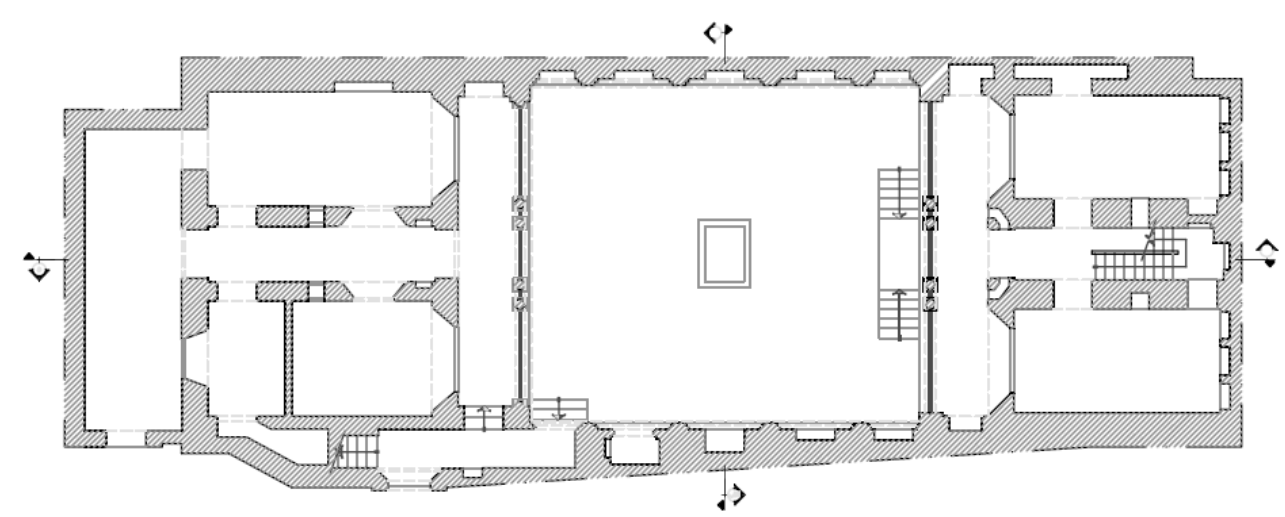

Plan of ground floor in Arazi House (Source: National Documents)

Building form can also have a great impact on harmonizing building with climate circumstances and balancing the transmission of external climactic weather to inside the house. Cold weather compresses the building and the warm weather coming from sunrise expands it in east-west direction. The best form of building is the one that loses the least calorie in the winter and receive the least heat from out in the summer; So, square plan is the best plan for buildings as having the most volume, it has the least external level (Kasmaei, 1387:116). 
Bulletin de la Société Royale des Sciences de Liège, Vol. 86, special edition, 2017, p. 831 - 844

\subsubsection{Yard}

In these houses, yards are located at the center and functions like a heart for the house. Different houses such as façade, balcony, corridor, moonlit, and podium are located by defined arrangement. All these are connected to the yard directly or indirectly.
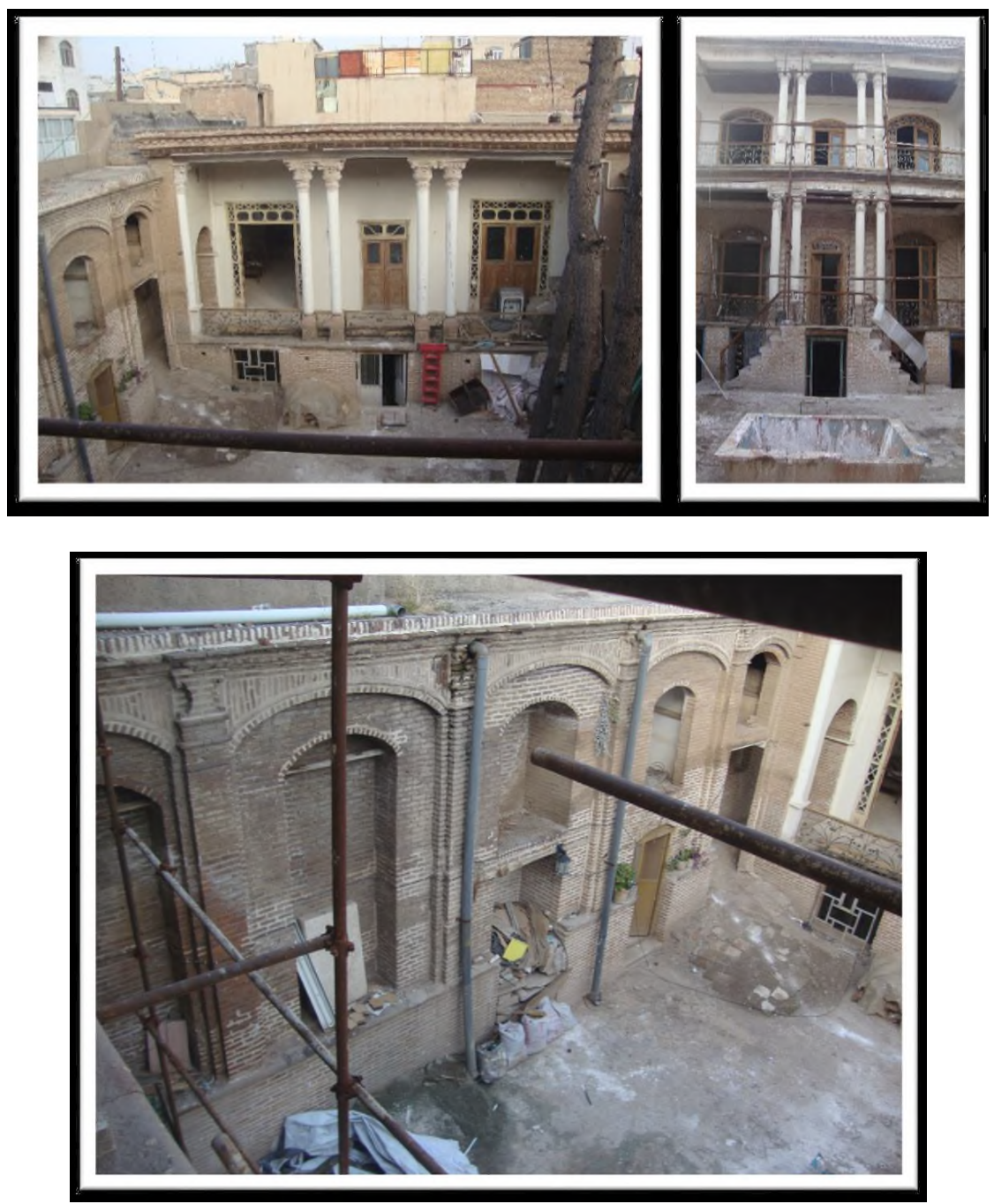

Photos from different views from Jalil Arazi house (Source: Writers)

Facades of houses have their own special independent character and appearance and are not directly connected to yard and other spaces but it connects the yard through some other spaces. All closed spaces are connected to the yard indirectly through closed spaces. This very way of simultaneous presence in one location caused the house to enjoy variety of sizes. The combination of vertical and horizontal levels of space in each side of the yard form different spaces for different private and public activities based on life style resembling a net (Haeri Mazandarani, 1387: 87). 
Main level differences of affected by climate in these houses include underground, yard, down house, upper house, and roof. Large differences of height also include pool house, Shahneshin, three door room, closet and porch. In historical-local houses, spaces are designed in a way that they can be suitable for uses in private or public spaces such as hosting, sleeping, food, and sitting through all the year without cooling or heating instruments. Rooms in these houses were designed in way to naturally be cool, warm or rooms of curran, etc. local winds had caused the dwellers to use these feature for conditioning.

Muslim dwelling historical houses were being divided in two parts: A part for men and hosting them and the part for women and children.

There are three different space qualities in different public and private realms that are designed as a complementary for each other. All three spaces-open, closed and vovered- are usable and can be utilized in combination. The design of these housed used to include both life style in large scales and spatial construction from small to large of them.

\subsubsection{The role of traditional materials in sustainability}

\subsubsection{The role of traditional materials in sustainability}

Each of the materials used in architecture have different physical features against forces. Although in the past, these has not been accessibility to all kinds of materials and people needed to apply the local materials according to their economic and regional circumstances.

\subsubsection{Brick and Adobe}

Adobe is the most used material in Iranian architecture in most regions in the country. One of the reasons for using it has been its accessibility without any need for fuel. Thus, people used to enhance its quality by including sand or clay of high adherence and decrease its shortages. Application of herbal leaves or camel wool in the adobe used to enhance its sustainability against humidity. Also, rubble enhance the sustainability and strength of adobe. 


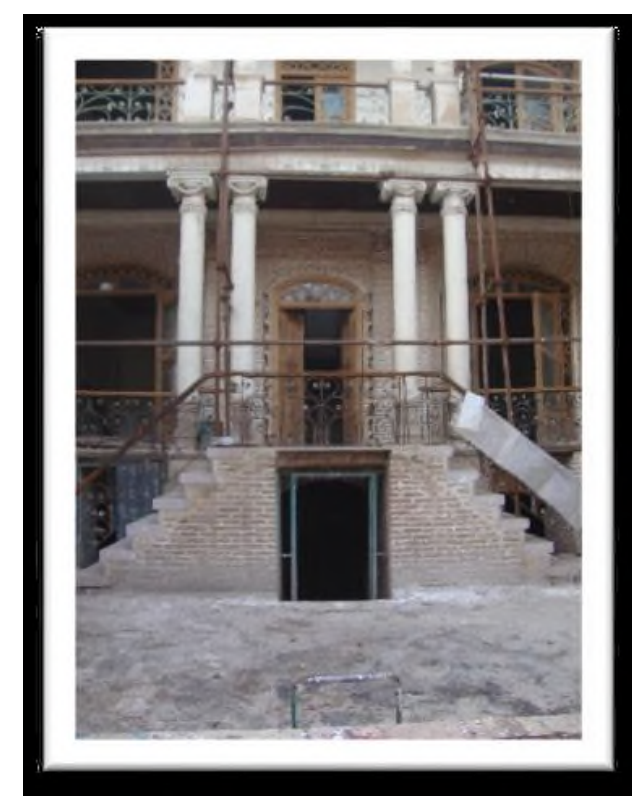

Jalil Arazi House (Source: Writers)

\subsubsection{Stone}

In Iranian architecture sedimentary rocks were used for final levels of buildings, as thet have little sustainability against humidity. Azar stones were used for walls and base building and Marmar were used for internal spaces.

\subsection{The necessity of attention for historical houses and textures}

Reminiscent houses of past centuries are some of the invaluable heritages of our ancestors that can be studied from different vies such as architectural, cultural and social aspects. Once being used for dwelling, these houses are now turned into very worthwhile cultural, artistic, and historical heritages in brick by brick of which the memories of golden Tabriz, and brave and intellectual men and women are curved. We should know that taking care of these heritages is a civil duty. Art and culture authorities along with regional administers have more responsibility in this regard as mending and preserving these heritages takes a lot of investments where the will of managers is a must.

In defining historical texture one should say that any historical building in the city can be considered as worn-out but not every historical texture is a historical texture. Thus, the domain of historical texture is more vast than worn-out texture; historical texture can include the wornout one (Shoaei, 1380: 64). Thus, historical buildings in cities and villages stand for Iranian civilization and culture as documents from history as a representative of our ancestors' identity. These textures encompass national architectural and urban values and reminiscent of ethnic memories and works of art belonging to contemporary and future generations which are not replacable (Satipipour, 1385: 237). 
Historical buildings are of great importance for urbanizing; one of the reasons is the known centrality for unifying the city. Old texture of physical, historical and cultural values is the best sign of urban identity. Life and growth of this texture obstructs the internal wearing of cities while excessive development defines the texture (Habibi et al, 1386: 20).

\section{Decorative and structural features of Ghajar buildings}

Studying Jalil Arazi as a case from among population of Ghazjar buildings particularly in Naseri era, some features can be identifies in it that is common is most of these buildings:

\subsection{Tile decorations}

Tile is one of the fine methods is all lands of Islamic area. The development of tiling started from the small elements sticking to external brick facades of buildings and attained its highest points in eight's and ninth's era. Iranian tile especially that of Islamic era is well-known worldwide. Western art affected Ghajar tiling deeply; New paintings known as "London flower" is designed in tiles this era that was not common before. Some colors are also unprecendented. The designs of these tiles are mostly derived from nature. In Ghajar era, a relative evolution happened in painting and subject of them. Most of the tiles include historical subjects or everyday life of the court. One of the innovations of the era is the use of the color red in tiling that was not common before. Glaze is one of the main parts of tile. It is a glasslike cover featuring two actions: decorative and functional ones. Not only are glazed tiles used for decoration, but they also protect the building against humid and water (Bemanian, Momeni, Soltamnzade, 1390).

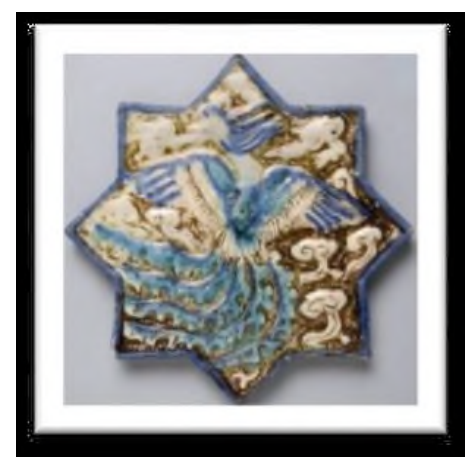

A sample of Ghajar Tiles

\subsection{Internal façade: tiling and stucco}

The main product of Iranian Architecture in Ghajar era is its mirror works. Interior façade decorations of the era also include stucco and tiling in internal facades. Passing through this era specially by entering Pahlavi era, complex decorations give way to simple ones as a result of the speed of constructions and the use of new materials (Saremi, 1376). 


\subsection{Color Glass works}

Glass works of color that are part of Ghajar decorative art have great impacts along with the comfort and releasing tensions. Color glass works in Ghajar buildings provides the dwellers with comfort and relaxation. This is one of the reasons that glass works are used in Islamic Iranian traditional buildings (Fander, Rahmati, Hadianpour, 1394).

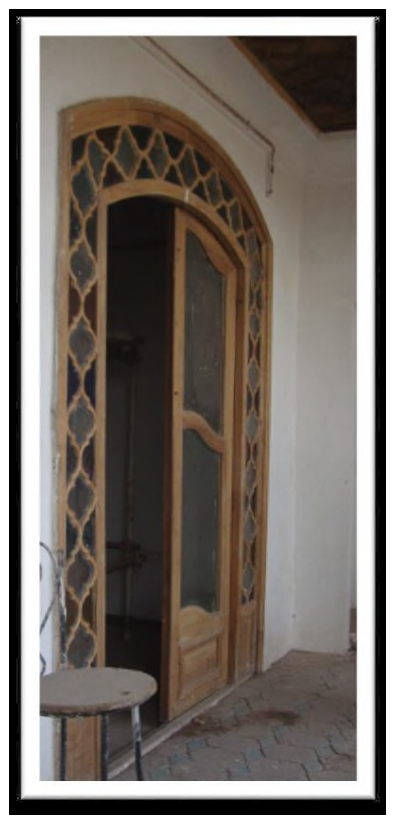

A case of glass works in Jalil Arazi house (Source: writers)

\subsection{Mirror works}

In this era mirror works used for decorations of palaces and tombs. Mirror works flourished in this era in such a way that different branches of mirror decorations formed; Matnbandi, rasmibandi, Mogharnas, gereh kari, and also painting and calligraphy at the back of glass are some of them. It was in the very era that beautiful objects such as Talar-e-Ayene, Shamsol-emare halls and rooms in Gholestan Palace formed (Aliabadi, Jamalian, 1391). 


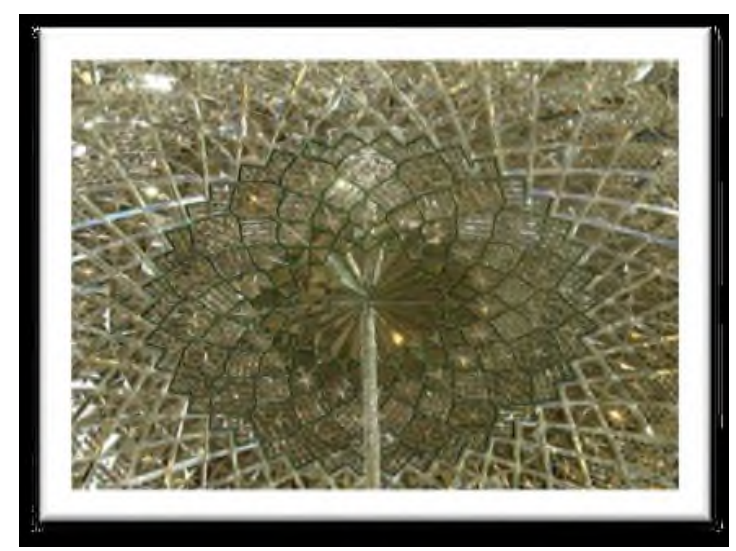

Mirrorworks of Ghajar dynasty (Source: writers)

\subsection{Sash Windows}

Sash windows are one of the main features in Iranian architecture from Safavid, Zand, Ghajar to Pahlavi eras which cannot be seen in today's houses. Sash windows have different architectural and decorative functions and usually are built of three, five, seven or sometimes ten door. Structurally, they have framework, Wadar, Pakhor, Patagh, and Longhes. Sash windows are the most special features of Iranian architecture. Sash window is a window that moves up and down vertically and its door is toward the yard. Its body is built of wood in Monabbat and Moshabbak works or Gerehchini and various plant and geometrical forms (including Gerehchini and Eslimi) locating then in color glasses. Sash windows are mostly rectangular. Their upper part reaches the roof in a rectangular, oval or multiplicative forms decorated by colored glass. This sort of door and window were common in tropical regions for arranging light and color in houses (Imami, Mahmoudi, 1393).

\subsubsection{Net form in sash windows and its application}

1. proving internal light, 2. Putting the external space in view, 3. Beauty in building façade, 4. Protecting privacy from external space, 5. Warding interfering insects off; colored glass wards insects off by its colored lights and sends them out. 


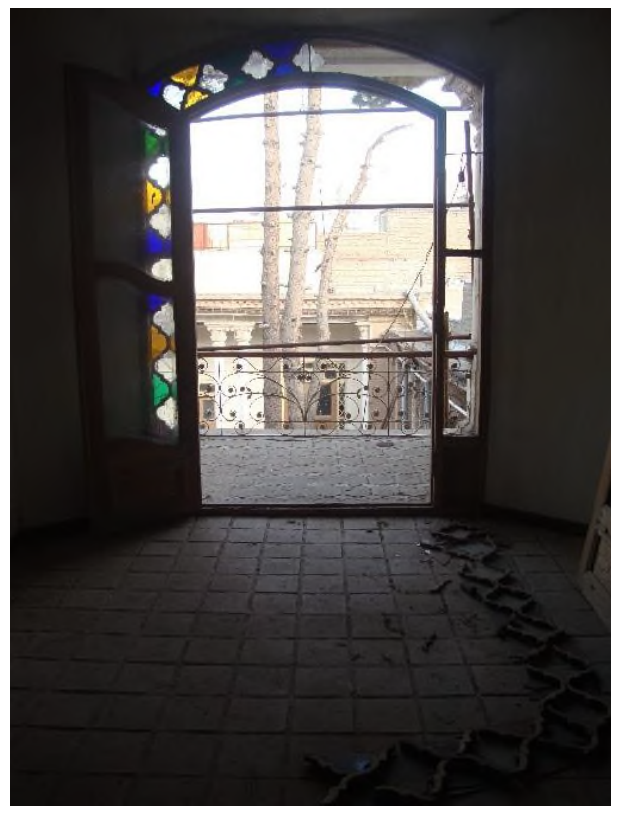

A sample sash window in Jalil Arazi (Source: Writers)

\subsubsection{The reason of using sash window in decorations}

A. light: these windows lets enough light to cross the window; not many not less.

B. Color psychology: different colors in these windows have their special psychological effect. Some of them neutralize others harsh effect providing the space a harmony in light. Red, Green, Yellow and Lajevardi are some of these colors each having different psychological effects.

D. Beauty: The sash windows enjoy various colors and various forms in gerehsazi that create unique compositions. The harmony between these geometrical nets and colored lights creates beauty.

E. Geometrical patterns in sash windows: considering animal and human figures as inappropriate in painting and other arts paved way for the use of geometrical and abstract forms in Islamic arts.

F. Privacy: sash windows prevents foreigners from being able to see inside the house.

J. Acoustic features: If the parts of a Gereh have various angles toward each other. These angles transmits sound which is a fact in acoustics. Hexagons have special acoustic features too. In nature, we can bring the example from beehive which functions for resonance or transmission of sound.

\section{Conclusion}

Internal design in historical buildings can be done in some ways in order to preserve and revive buildings: 
1. Sustainability of architecture and internal architecture.

2. Harmony with internal and the whole architecture

3. Modernity and innovation expressing era's features.

The thing that is obvious in all samples is the fact that if the designer understands the historical building, the internal design will form relative to material and spiritual values. That is, it can have an effective role preserving and introducing historical sites, while giving it a new life.

In this paper we sought to put traditional and cultural features first. The pattern of the design was the very historical building formed in order to protect the values of it.

An important note on the importance of internal design in reviving historical buildings is the fact that the designs can be provided based on the features of the same building. Thus the design if specific for that building only and won't be suitable for other buildings. In fact, originality of design is relative to environment and location.

Considering the limitations in the research, obviously the alterations in application of buildings of cultural, historical, and artistic value would be successful if the identity of it is preserved. Considering local-aboriginal features, the comprehensive existence of the building can be accessible via these deeds.

Main changes in the body and architecture and design of historical buildings is unavoidable. To use as tourist attraction, they need to be reconsidered and revives that they can have a good impact on this industry as well. This type of revival of architecture along with thought and cultural-social commitment is in a level that reveals the value of their preservation so that they can have a better future.

\section{Resources}

[1] Imami, Shapor, Mahmoudi, (1393), shah s=windows in Tabriz traditional houses in Ghajar era.

[2] Bemani, Mohammad reza, Soltanzadeh, Hossein, Momeni, Korosh, (1390), Examination of innovations in Ghajal tile patterns and decorations in mosque-schools.

[3] Haeri Mazandarani, Mohammadreza (1388), Home, culture, nature, Tehran: Research center for architecture and urban design

[4] Habibi, kiumarth, Porahmad, Ahmad, (1386), Renovation and improvement of old textures in Shiraz, Intikhab Pub, First Publication, Tehran

[5] Rahmati, Mohammad Ghaed, Hadian Pour, Mohammad, (1394), the effect of color glass worksand its psychological effect on the spirits of the internal audience: case study: Shiraz's Nasirol molk mosque.

[6] Sartippi pour, Mohsen (1385), Suitable technology for decreasing historical site's harms, the first conference on management of earchthquake in historical cities, 9-11 khordad, Yazd university. 
[7] Shamaei, Ali, (1380), the effect of Yazd's physical development on the historical parts of it, $\mathrm{PhD}$ dissertation, Tehran university.

[8] Saremi, Aliakbar. Sustainable values in Iranian architecture (1376).

[9] Aliabadi, Mohammad, Jamalian, Somayye (1391), Pathology of Mirror works in Ghajar buildings in Shiraz

[10] Kasmaei, Morteza, 1387. Climate and architecture, Isfahan: Kahk Pub.

[11] Ahmad, Y. (2006), "The scope and definitions of heritage: from tangible to intangible", International journal of heritage studies 12(03), pp 292-300.)

[12] Brolin, B. (1980), "Architecture in Context, New York", Van Nostrand Reinhold Company

[13] CABE .(2001), "Building in context New development in historic areas, Wiltshire, English Heritage". pp 622-644)

[14] ICOMOS (International council on monument and sites). (1964), Available: http://www.international.icomos.org/home.htm, Venice Charter, 2

[15] pekog lu, B.-a. I. (0222), "An architectural evaluation method for conservation of traditional dwellings", Building and Environment 14, pp 683-63.)

[16] Penn, W. (2007), "Sense of Place: Design Guidelines For New Construction In Historic Districts", A Publication of the Preservation Alliance for Greater Philadelphia

[17] Rai, Ruprama. (2008), "Threats To The Spirit Of The Place Urban Space And Squares", Historic City Core, Kathmandu, Institute for Technology in the Tropics and Sub Tropics 